\title{
Trypanosoma brucei gambiense
}

National Cancer Institute

\section{Source}

National Cancer Institute. Trypanosoma bruceigambiense. NCI Thesaurus. Code C125975.

A species of parasitic flagellate protozoa in the order Kinetoplastida. T. b. gambiense is transmitted by the tsetse fly and causes West African trypanosomiasis. Humans are the main reservoir for T. b. gambiense, but this species can also be found in animals. 